\title{
Diaphyseal Femur Fracture in Paediatric Age group: Outcome with fixation by Elastic Nailing System
}

\author{
Sagar Panthi ${ }^{1 *}$, Rishiswor Shrestha ${ }^{1}$, Jigyasu Pradhan ${ }^{1}$, Bikash Neupane$^{1}$, Ishory Bhusal ${ }^{2}$, Angelica Karki ${ }^{3}$
}

\author{
Author Info: \\ ${ }^{1}$ Department of Orthopaedics \\ and Traumatology, Rapti \\ Academy of Health Science, \\ Ghorahi, Dang, Nepal \\ ${ }^{2}$ Department of Surgery, Rapti \\ Academy of Health Science, \\ Ghorahi, Dang, Nepal \\ ${ }^{3}$ Department of Orthodontics \\ and Dentofacial Orthopaedics, \\ Rapti Academy of Health Science, \\ Ghorahi, Dang, Nepal

\section{*Corresponding Author: \\ Dr. Sagar Panthi; \\ Associate Professor \\ Email/Contact: +9779857036678; \\ drsagarmsortho@gmail.com}

\begin{abstract}
Background: Diaphyseal femur fracture in paediatric age group account for $1.6 \%$ of all paediatric fractures. Fracture fixation by elastic nail provides three point fixation. This study aims to assess the outcome of diaphyseal femur fracture in paediatric age group from 5 to 15 years treated with titanium elastic nailing system.
\end{abstract}

Methods: Thirty six patients with diaphyseal femur fracture were treated with titanium elastic nailing system from November 2018 to August 2020 was analyzed prospectively. All the patients were followed up for six months for the study. Final outcome was evaluated at six months.

Results: The mean time of fracture union was 9.12 weeks. Two patients had limb lengthening of $6 \mathrm{~mm}$ and $8 \mathrm{~mm}$ respectively. One patient had $1 \mathrm{~cm}$ of shortening and 8 degree of varus angulation and 9 patients had bursitis over nail insertion site. According to Flynn grading 26 cases have excellent results (72.22\%) and 10 cases have satisfactory results (27.78\%).

Conclusion: Diaphyseal femur fracture can be treated with elastic nailing system with early mobilization and good functional outcomes.

Keywords: Diaphyseal femur fracture, Elastic nail, Fracture union, Titanium elastic nailing system

\section{INTRODUCTION}

Diaphyseal femur fracture in paediatric age group account for $1.6 \%$ of all paediatric fractures. ${ }^{1}$ Due to rapid recovery and shorter immobilization diaphyseal femur fracture in a paediatric age group are managed with operative treatment rather than conservative treatment. ${ }^{2}$ There are various method for treatment of paediatric diaphyseal femur fracture that includes early reduction and hip spica application, traction followed by hip spica application, elastic stable nail, plate and screw fixation and external fixators in case of open fractures. ${ }^{3,4}$ Small children less than 5 years old can be managed with early reduction and hip spica application. Previously age between 5 to 13 years were well managed with traction followed by hip

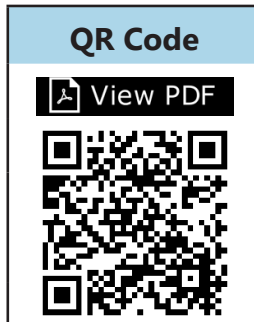

Scan Me

Received: 2 December 2020; $\quad$ Accepted: 26 January 2021;

Accepted: 26 January 2021; How to cite this article in Vancouver Style?

Panthi S, Shrestha R, Pradhan J, Neupane B, Bhusal I, Karki A. Diaphyseal Femur Fracture in Paediatric Age group: Outcome with fixation by Elastic Nailing System. Europasian J Med Sci. 2021;3(1):1-5. https://doi.org/10.46405/ejms. $\underline{\text { vii1.258 }}$

\section{Disclaimer}

Conflict of Interest: None Declared;
Source of Support: Nil

Copyright (C) 2021 by author(s). This work is licensed under the terms and condition of Creative Commons Attribution International License 4.0 (@) () (http://creativecommons.org/licenses/by/4.0/) which permits unrestricted use, distribution, and reproduction in any medium, provided the original work is properly cited. This is an open access publication, and can be downloaded freely from the website of the Journal: www.europasianjournals.org. The Journal as well as publisher remain neutral with regards to any jurisdictional claims in any published articles, its contents and the institutional affiliations of the authors. The Europasian Journal of Medical Sciences (EJMS) (www.europasianjournals.org) is an official Journal of Nirvana Psychosocial Care Center \& Ressearch Institute (www.nirvanapscc.com). 
recovery and shorter immobilization with operative management. Adolescent children age above 15 years are treated with closed/open intramedullary interlocking nail. ${ }^{5}$

Antegrade intramedullary interlocking nail may lead to avascular necrosis of femoral head whereas external fixators may cause pin-tract infection. Plate and screw fixation requires extensive soft tissue dissection. Excellent to good results have been reported by several researchers with retrograde flexible (Ender) or elastic (Nancy) nailing for diaphyseal femur fracture in paediatric age group..$^{6-10}$

Elastic nail converts traction forces into compressive forces on fracture site when two bent nails crossing each other and within the canal it also provides three point fixation. The elasticity of elastic nail promotes callus formation by promoting oscillation and limited stress shielding effect on fracture site. The advantages of elastic nailing includes less soft tissue dissection, low chance of infection, immediate fracture stabilization, early mobilization and early return to daily activities. ${ }^{11,12}$

The aim of this prospective study was to assess the outcome of diaphyseal femur fracture in paediatric age group from 5 to 15 years treated with titanium elastic nailing system.

\section{MATERIALS AND METHODS}

A prospective interventional study was conducted in Rapti Academy of Health Science Ghorahi, Dang, Nepal from the period extending from November 2018 to August 2020. Forty patients with age between 5 to 15 years with closed diaphyseal fracture of femur were included in our study. Four patients lost for final follow-up and were excluded from study. Child with weight more than $70 \mathrm{~kg}$, Sclerotic and narrow femoral canal, Open fracture, Fracture extending into proximal and distal ends, Pathological fractures, Lost follow up patient were excluded. Permission from Institutional review committee was obtained. All included patients were treated with titanium elastic nailing system.

All surgeries were performed under regional or general anaesthesia. All patients were placed in fracture table and traction was applied under fluoroscopic guidance for fracture reduction. The involved side was disinfected and drapped. Proper size elastic nail was taken and tip of nail were bent to prevent perforation of cortex. Two stab incision were given on lateral and medial side of distal femur, $2 \mathrm{~cm}$ proximal to distal femoral physeal plate under fluoroscopic guidance. One nail was
Table 1: Flynn Criteria

\begin{tabular}{|c|c|c|c|}
\hline Criteria & Excellent & Satisfactory & Poor \\
\hline $\begin{array}{l}\text { Limb length } \\
\text { inequality }\end{array}$ & $<1 \mathrm{~cm}$ & $<2 \mathrm{~cm}$ & $>2 \mathrm{~cm}$ \\
\hline Malalignment & $\begin{array}{l}<5 \\
\text { degree }\end{array}$ & $<10$ degree & $\begin{array}{l}>10 \\
\text { degree }\end{array}$ \\
\hline Pain & None & None & Present \\
\hline Complication & None & Minor & Major \\
\hline
\end{tabular}

driven towards femoral neck and other towards greater trochanter. The nail was pre-bent before insertion due to its flexible nature. Toe touch weight bearing was started at first post-operative day. Suture removal was done on 2 weeks after surgery. Final evaluation was done both clinically and radiologically at 6 months. Fracture pattern, duration of hospital stay, duration of fracture union and for functional outcome Flynn Criteria (Table 1) was used..$^{11}$ All data were entered and analyzed using SPSS 21.

\section{RESULTS}

Out of 36 patients, 23 were male (63.89\%) and 13 were female $(36.11 \%)$. Right side was involved in 19 patients $(52.77 \%)$ and left side was involved in 17 patients (47.23\%). 16 fractures were transverse pattern (44.44\%), 11 fractures were oblique pattern (30.56\%), 6 fractures were comminuted pattern (16.67\%) and 3 fractures were spiral pattern (8.33\%) (Table 2).

The mean hospital stay was 6 days ranging from 4 to 8 days. Mean time of fracture union was 9.12

Table 2: Patients Characteristics

\begin{tabular}{ll}
\hline Parameters & No. of Cases (\%) \\
\hline Gender & $23(63.89)$ \\
Male & $13(36.11)$ \\
Involved side & $19(52.77)$ \\
Right & $17(47.23)$ \\
Left & \\
Fracture pattern & $16(44.44)$ \\
Transverse fracture & $11(30.56)$ \\
Oblique fracture & $6(16.67)$ \\
Comminuted fracture & $3(8.33)$ \\
Spiral fracture & \\
\hline
\end{tabular}

weeks ranging from 6 to 13 weeks. In 7 patients closed reduction was failed and open reduction was carried via lateral approach to reduce the fracture. One patient had $1 \mathrm{~cm}$ of shortening and 8 degree of varus angulation at final follow-up. Two patients had limb lengthening of $6 \mathrm{~mm}$ and $8 \mathrm{~mm}$ respectively at final follow-up. Nine patients had 


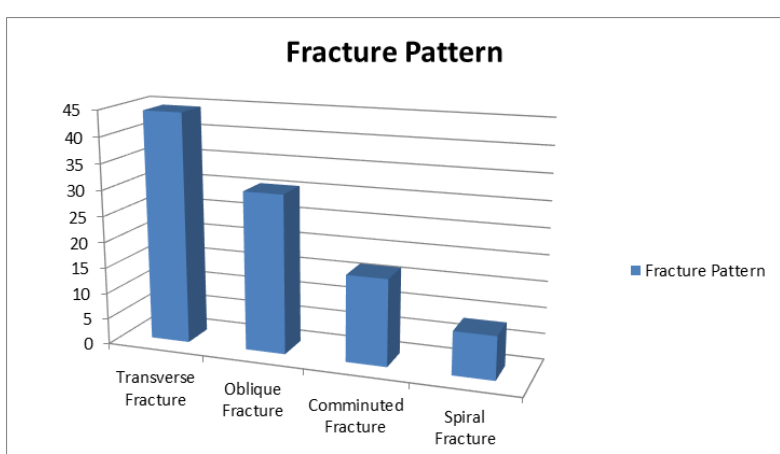

Figure 1: Fracture Pattern

bursitis over the nail insertion site. Knee range of motion was recovered in all cases. There was no cases of Nonunion, Delayed union, Nail breakage and infection. According to Flynn grading 26 cases have excellent results and 10 cases have satisfactory results at final follow-up. (Table 3 )

Table 3: Flynn grading at final follow-up

\begin{tabular}{lll}
\hline Flynn Grading & Number & Percentage (\%) \\
\hline Excellent & 26 & 72.22 \\
Satisfactory & 10 & 27.78 \\
Poor & 0 & 0 \\
\hline
\end{tabular}

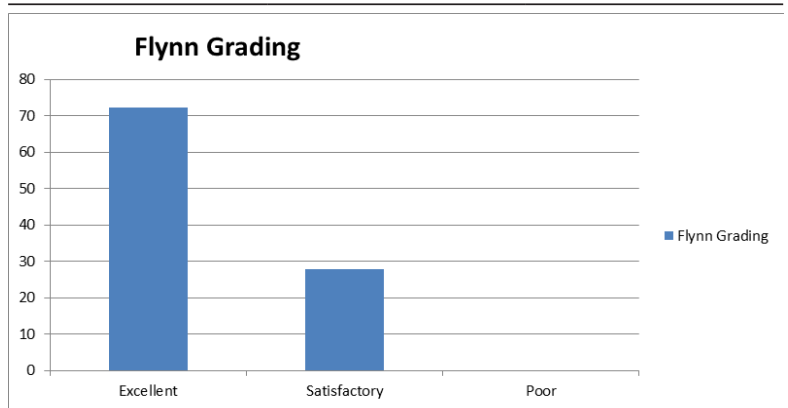

Figure 2: Flynn grading

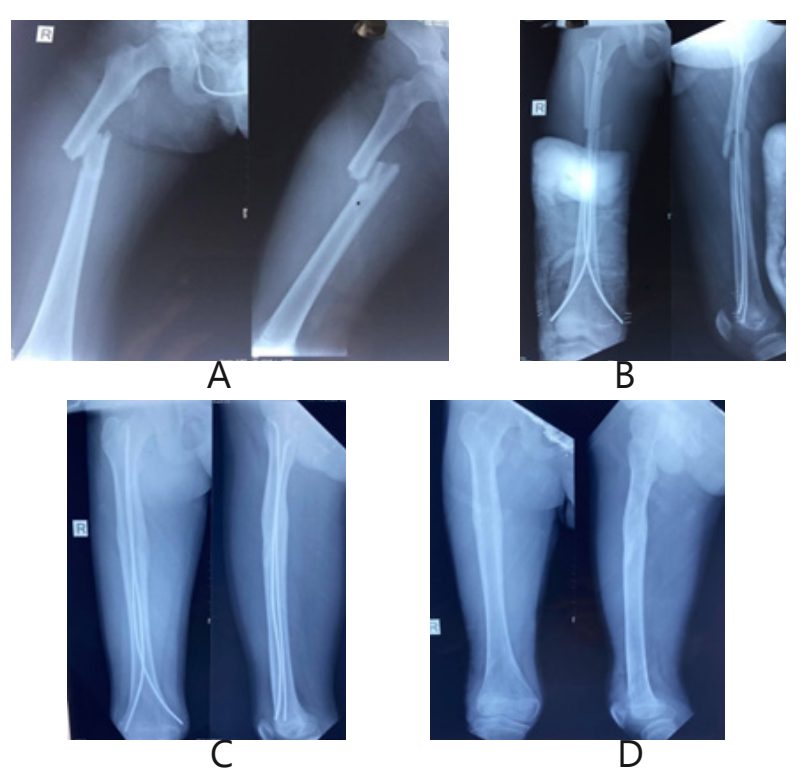

Figure 3: (A) Pre-op radiograph (B) Immediate postop (C) 6 months follow-up x-ray (D) After implant removal

\section{DISCUSSION}

Ideal mode of treatment of diaphyseal femur fracture remains controversial. It depends on age of children, type and location of fracture, knowledge of expert surgeon as well as financial conditions among which titanium elastic nail is the good option for management of diaphyseal femur fracture in school children. ${ }^{13}$ In recent studies, treatment of diaphyseal femur fracture move towards operative measures since these measures have the advantages of quick recovery, faster rehabilitation as well as low psychological impact on children. ${ }^{5}$ While inserting flexible elastic nail, reaming is not required thus, it preserves the endosteal blood supply which helps in early union of fracture. ${ }^{14}$

We evaluated 36 patients, among them $63.89 \%$ were male and $36.11 \%$ were female. In the study done by Ligier et al., there were $67.7 \%$ boys and $32.3 \%$ girls out of 118 cases. ${ }^{15}$ In the study done by Gamal El-Adl et al there were $72.7 \%$ male and $18 \%$ female out of 66 patients. ${ }^{16}$ Compare to female, male are more active in outdoor activities.

Ligier et al. did a study of 118 cases and among them $30 \%$ cases have transverse fracture, $44 \%$ cases have oblique fracture, $16 \%$ cases have spiral fracture and $10 \%$ cases have comminuted fracture. ${ }^{15}$ In our study, $44.44 \%$ cases had transverse fracture, $30.56 \%$ cases had oblique fracture, $16.67 \%$ cases had comminuted fracture and $8.33 \%$ had spiral fracture.

Mean hospital stay was 6 days. We treated most of the patient by closed methods so this results into less hospital stay. Reeves et al compared operative versus conservative management in paediatric diaphyseal femur fracture and concluded that operative treatment fractures have shorter hospital stay than the fractures that were managed conservatively 26 versus 9 days. ${ }^{17}$

Mean time of fracture union was 9.12 weeks. In the study done by Sink et al, the mean time of fracture union was 12 weeks. In their study, they included 27 patients with diaphyseal femur fracture who were managed with submuscular plating. ${ }^{18}$ However, submuscular plating have less stability than flexible nail even though the length of hospital stay was comparable with both treatment techniques. In the 
study done by Cramer Kathryn E et al all fractures united in 12 weeks and they evaluated 57 femoral shaft fractures that were treated with Ender's nail in age less than 14 years. ${ }^{19}$

Two patients had limb lengthening of $6 \mathrm{~mm}$ and $8 \mathrm{~mm}$ respectively. Limb lengthening is a common complication of paediatric femoral fractures this is because of increasing vascularity in growth plate at the time of fracture union. The limb lengthening varies from $4 \mathrm{~mm}$ to $2.5 \mathrm{~cm}$ in children with age group between 2 to 10 years of old. ${ }^{20}$

One patient had one $\mathrm{cm}$ of shortening and 8 degree of varus angulation. This is because; the fracture was located in proximal one third which results into varus angulation and a $\mathrm{cm}$ of shortening. The acceptable varus angulation is less than 10 degrees in older children. ${ }^{19}$ In the study done by Wallace and Hoffman, angulated femoral shaft fractures of age less than 13 years were corrected in $85 \%$ cases. $^{21}$

In the study done by K.C. et al out of 28 patients, mean age was 8.14 years, Mean Hospital stay was 4 days and mean fracture union time was 9.57 weeks which is similar to our study. ${ }^{22}$

Nine patients develop bursitis over the nail insertion site. These are the minor complications and occur due to friction of nail and skin. There were no cases of Non-union, Delayed union, Nail breakage and Infection, regarding complications.

Flexible elastic nail maintains length, alignment and it prevents rotation which stimulates the formation of external callus that provide strength to bone. ${ }^{15}$

\section{CONCLUSION}

Management of paediatric diaphyseal femur fracture with elastic nail is safe and stable methods. It considerably decreases the length of hospital stay, faster fracture healing and early return to daily activities.

\section{REFERENCES}

1. Von Heideken J, Svensson $T$, Blomqvist $P$, HaglundÅkerlind $Y$, Janarv PM. Incidence and trends in femur shaft fractures in Swedish children between 1987 and 2005. Journal of Pediatric Orthopaedics. 2011;31(5):512-9. 10.1097/BPO.0b013e31821f9027 [Google Scholar] [PubMed]

2. Carey TP, Galpin RD. Flexible intramedullary nail fixation of pediatric femoral fractures. Clin Orthop Relat Res. 1996;332:110-118. 10.1097/00003086199611000-00015 [Google Scholar] [PubMed]
3. Kregor PJ, Song KM, Routt Jr ML, et al. Plate fixation of femoral shaft fractures in multiply injured children. J Bone Joint Surg Am. 1993;75:1774-1780. 10.2106/00004623-199312000-00006 [Google Scholar] [PubMed]

4. Beaty JH, Austin SM, Warner WC, et al. Interlocking intramedullary nailing of femoral-shaft fractures in adolescents: preliminary results and complications. J Pediatr Orthop. 1994;14:178-183. 10.1097/01241398-199403000-00009 [Google Scholar] [Full Text]

5. Canale ST. Fracture and dislocation in children. In: Canale ST, Beaty JH, eds. Campbell's Operative Orthopaedics. 11th ed. Philadelphia: Mosby; 2007: 1651-1661. [Google Scholar]

6. Heinrich SD, Drvaric DM, Darr K, et al. The operative stabilization of pediatric diaphyseal femur fractures with flexible intramedullary nails: a prospective analysis. J Pediatr Orthop. 1994;14:501-507. 10.1097/01241398-199407000-00016 [Google Scholar] [PubMed]

7. Fein LH, Pankovich AM, Spero CM, et al. Closed flexible intramedullary nailing of adolescent femoral shaft fractures. J Orthop Trauma. 1989;3:133141.10.1097/00005131-198906000-00008 [Google Scholar] [PubMed]

8. Kissel EU, Miller ME. Closed-ended nailing of femur fractures in older children. J Trauma. 1989;29:15851588. 10.1097/00005373-198911000-00020 [Google Scholar] [PubMed]

9. Mann DC, Weddington J, Davenport K. Closed Ender nailing of femoral shaft fractures in adolescents. J Pediatr Orthop. 1986;6:651-655. 10.1097/01241398198611000-00002 [Google Scholar] [PubMed]

10. Greisberg J, Bliss MJ, Eberson CP. Social and economic benefits of flexible intramedullary nails in the treatment of pediatric femoral shaft fractures. Orthopedics. 2002;25:1067-1070. https://doi. org/10.3928/0147-7447-20021001-18 [Google Scholar] [PubMed] [Full Text]

11. Flynn JM, Heresko T, Reynolds RA, Blasier RD, Davidson R, Kasser J. Titanium elastic nails for pediatric femur fractures: a multicenter study of early results with analysis of complications. J Pediatr Orthop. 2001;21(1):4-6. 10.1097/00004694200101000-00003 [Google Scholar] [PubMed]

12. Huber RI, Keller HW, Huber PM, Rehm KE. Flexible intramedullary nailing as fracture treatment in children. J Pediatr Orthop. 1996;16(5):602-5. 10.1097/00004694-199609000-00011 [Google Scholar] [PubMed]

13. Staheli L, Sheridan G. Early spica cast management of femoral shaft fractures in young children. A technique utilizing bilateral fixed skin traction. Clin Orthop Relat Res. 1977;126:162-166. [Google 
Scholar] [PubMed]

14. Pankovich AM, Goldflies ML, Pearson RL. Closed Ender nailing of femoral-shaft fractures. J Bone Joint Surg Am. 1979;61:222-232. [Google Scholar] [PubMed]

15. Ligier JN, Metaizeau JP, Prevot J, Lascombes P. Elastic stable intramedullary nailing of femoral shaft fractures in children. J Bone Joint Surg [Br]. 1988; 70B:74-77. 10.1302/0301-620X.70B1.3339064 [Google Scholar] [PubMed]

16. Gamal El-Adl, Mohamed F, Mostsfa A Khalil, Ahmed Enan. Titanium elastic nail fixation for pediatric femoral fractures. Acta Orthop. Belg. 2009; 75:512520. [Google Scholar] [PubMed] [Full Text]

17. Reeves RB, Ballard RI, Hughes JL. Internal fixation versus traction and casting of adolescent femoral shaft fractures. J Pediatr Orthop. 1990;10:592-595. 10.1097/01241398-199009000-00004 [Google Scholar] [PubMed]

18. Sink EL, Hedequist D, Morgan SJ. Results and technique of unstable pediatric femoral fractures treated with submuscular bridge plating. J

Pediatr Orthop. 2006;26:177-181. 10.1097/01. bpo.0000218524.90620.34 [Google Scholar] [PubMed]

19. Cramer $K E$, Tornetta $P$, Spero $C R$. Ender rod fixation of femoral shaft fractures in children. Clin Orthop Relat Res. 2000;376:119-123. 10.1097/00003086200007000-00017 [Google Scholar] [PubMed]

20. Shapiro F. Fractures of the femoral shaft in children: the overgrowth phenomenon. Acta Orthop Scand. 1981;52:649-655. [Google Scholar] [PubMed]

21. Wallace ME, Hoffman EB. Remodeling of angular deformity after femoral shaft fractures in children. J Bone Joint Surg. 1992;74:765-769. 10.1302/0301-620X.74B5.1527131 [Google Scholar] [PubMed]

22. KC KM, RC DR, Acharya P. Pediatric femoral shaft fractures treated by flexible intramedullary nailing. Chinese Journal of Traumatology 18 (2015) 284-287. https://doi.org/10.1016/j.cjtee.2015.05.002 [Google Scholar] [Full Text] 